Proceedings of the Institution of
Civil Engineers
Municipal Engineer 157
June 2004 Issue ME2
Pages $77-85$
Paper 13287
Received $26 / 02 / 2003$
Accepted $28 / 11 / 2003$
Keywords:
local government/municipal \& public
service engineering/social impact/
town \& city planning

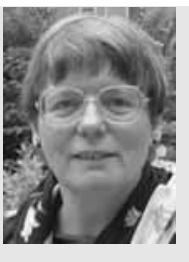

Clara Greed

Professor, School of Architecture

and Planning, University of the West of England, Bristol, UK

\title{
Public toilets: the need for compulsory provision
}

\section{Greed PhD, MRTPI, MRICS, FCIOB, FRGS}

There is no mandatory requirement for local authorities to provide public toilets. Yet, it is argued, they are a vital component in creating accessible, sustainable and comfortable cities for all. In this paper the reasons for compulsory standards are explained, and the underlying problems of current provision and regulation are investigated. The nature of a spatial toilet strategy in respect of the adequate distribution and location of public toilets is outlined. Changes in the regulatory and organisational aspects of public toilet provision are proposed that would result in a better standard of facilities for twenty-first century needs.

\section{INTRODUCTION}

\section{I.I. Scoping the problem and its solutions}

In this paper it is argued that the provision of public toilets is an essential factor in creating sustainable and accessible towns and cities. First, the reasons for mandatory provision, as opposed to the current freedom for local authorities to apply optional standards as they wish, are explained. The need for compulsory provision and standards is set within the wider urban policy context. Toilet provision is arguably a high-level strategic policy issue with implications for the environment, health, tourism, and transport strategy. The situation is bad for everyone, but as explained, lack of provision affects some groups more than others, especially women, the elderly and people with disabilities.

Following the introductory section, s. 2 sets out why the problem of lack of public toilet provision should be taken seriously with reference to key urban policy issues. In s. 3 the causes of the present problem, particularly the lack of any statutory requirement for local authorities to provide public toilets, are explained. Section 4 addresses, in summary, what might be done to ameliorate the situation, by recommending the development of a toilet strategy that would provide policy guidance on the distribution, location and siting of public toilet facilities. (Details of toilet policy and design recommendations are to be found in Reference 1, but the purpose of this paper is to concentrate on the need for legislative and regulatory reform to bring about such change.) Section 5 explains how this might be done, by means of legislative reform and regulatory control. However, change, it is argued, cannot be achieved unless cultural and attitudinal change takes place which would result in the issue being taken seriously and financed adequately as a valid component of highlevel urban policy.

\section{I.2. Definitions}

Public toilets may be defined as comprising both traditional onstreet public toilets (usually run by the local authority) and offstreet toilets to which the public has access (run by private-sector providers) such as those in shopping malls, sports centres, and railway stations. The term 'away from home toilets' as coined by the British Toilet Association is used to include all categories of public toilet. $^{2}$ The word 'toilet' is preferred to 'lavatory' because it is understood internationally and encompasses all sorts of facilities ('Ladies' and 'Gents', cubicles, urinals and automatic public conveniences (APCs)). This paper draws on toilet research undertaken by the author, from a predominantly town planning perspective. ${ }^{1,3,4}$

\section{REASONS TO TAKE THE TOPIC SERIOUSLY}

\section{I. Supporting urban sustainability policy}

Over $40 \%$ of public toilets have been closed over the past ten years (Fig. 1), and some local authorities have no toilets at all. If the Government wants to encourage people to leave their cars at home and use public transport then there is a need to provide public toilets at main transport termini. Provision needs to be made for pedestrians, cyclists and public transport users who, unlike car drivers, cannot speed to the nearest motorway service station toilet. Closure of toilets at bus stations, which are

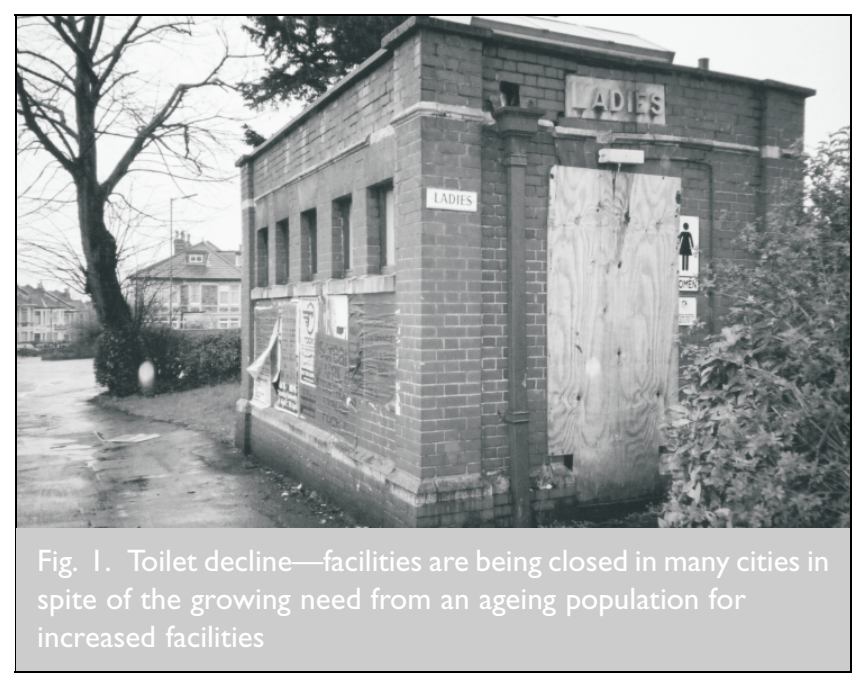


effectively main gateways to the city, can undermine high-level urban sustainability policy by further discouraging people from using public transport. Lack of provision affects a wide range of people including tourists, commuters, shoppers, visitors, the elderly, parents with small children, the pregnant and the disabled and anyone who has frequent need of a toilet.

\subsection{Serving the 24-hour city}

Many local authorities have encouraged the 'evening economy' by relaxing planning controls. This change, along with the liberalisation of licensing controls, has resulted in increased numbers of bars, clubs and pubs in central areas. But there has been lack of provision of adequate back-up facilities and services such as lighting, public transport, policing and toilets to meet the challenges of these changes. Reduced opening hours of existing public toilets, plus complete closure of facilities in some city centres, has resulted in increased street urination. ${ }^{5}$ However, some city-centre managers and police favour closure as a means of controlling vandalism, graffiti, cottaging and drug-taking in downtown toilets. ${ }^{6}$

In an attempt to curb street fouling, some local authorities have been introducing male-only facilities in the form of open-air street urinals for use by late-night drinkers. This approach discourages women, the disabled, and families making use of the city streets in the evenings. Authorities have been criticised for taking limited resources away from daytime toilet provision, and putting more emphasis upon the needs of evening drinkers than daytime shoppers and commuters, most of whom would prefer to see more traditional toilets for all. ${ }^{7}$ Legislation that required more balanced and equal provision would result in more adequate day and night facilities for all sectors of society.

\subsection{Meeting community needs}

All over the country there are local groups fighting to protect 'their' toilets. Closure of public conveniences is one of the topics about which local authorities receive the most complaints (along with refuse collection, dog fouling and vandalism). With an ageing population, and increasing disablement, public toilets are becoming more, not less, important in many areas. Under the requirements of Part III of the Disability Discrimination Act 1995 (DDA), which come into force on 1 October 2004, service providers are expected to make 'reasonable adjustments' to all existing public toilets to make them disabled accessible. ${ }^{8}$ Anticipating this, some local authorities and private providers of public toilets are closing their toilet facilities altogether to save having to upgrade them. ${ }^{7}$ This situation would not have arisen had there been mandatory requirements for public toilet provision for all.

\section{WHAT ARE THE CAUSES OF THE PROBLEM?}

\section{I. The legal basis}

The crux of the problem is that there is no statutory requirement that public toilets must be provided. The 1936 Public Heath Act (still extant), s. 87 gives local authorities permissive powers to provide public toilets if they so wish, but there is no mandatory requirement to do so. In other words it was left to the discretion of a local authority to meet the needs of its citizens.

\subsection{Regulatory control}

If local authorities do choose to provide toilets then they are subject to a range of Building Regulations and British Standards controls (along with all other toilets). The statutory guidance documents British Standard BS 6465 on sanitary installations (Parts I and II), ${ }^{9}$ and the linked Approved Document G of the Building Regulations ${ }^{10}$ provide national guideline standards for toilet provision. While Part I of BS 6465 is concerned with the numbers of toilet facilities per type of building (based mainly on floor space or number of employees and users), Part II concentrates on toilet dimensions and plumbing details. In contrast to the pages of tables setting standards for toilet provision within buildings, guidance on public toilet provision is contained in one sentence only in s. 7.4 of Part I, which states: 'The provision of sanitary appliances in public toilets should be determined according to local needs.'

Thus there is no guidance in BS 6465 Part I on the numbers, distribution and location of on-street public toilets, presumably because it was assumed that local authorities could make their own informed decisions on this. In the past, a wide range of types of public toilet have been provided as and where they have been needed, typically in town centres, main transport interchanges, in public parks, local centres, tourist centres and on busy thoroughfares (Fig. 2). Currently a revision committee for BS 6465 Part I (of which the author is a member) is at work. Attention is being given to the development of standards for public toilets in terms of location, distribution and numbers, as well as improving the levels of toilet provision for all types of buildings including shops, offices, factories and leisure venues.

Although there are standards governing the design and plumbing aspects of public toilets, they apply only to new toilet developments, or in some cases to substantial refurbishments. The standards are not retrospective (unlike aspects of DDA requirements), but the vast majority of public toilet provision is old and the building of new public toilets is a rare event.

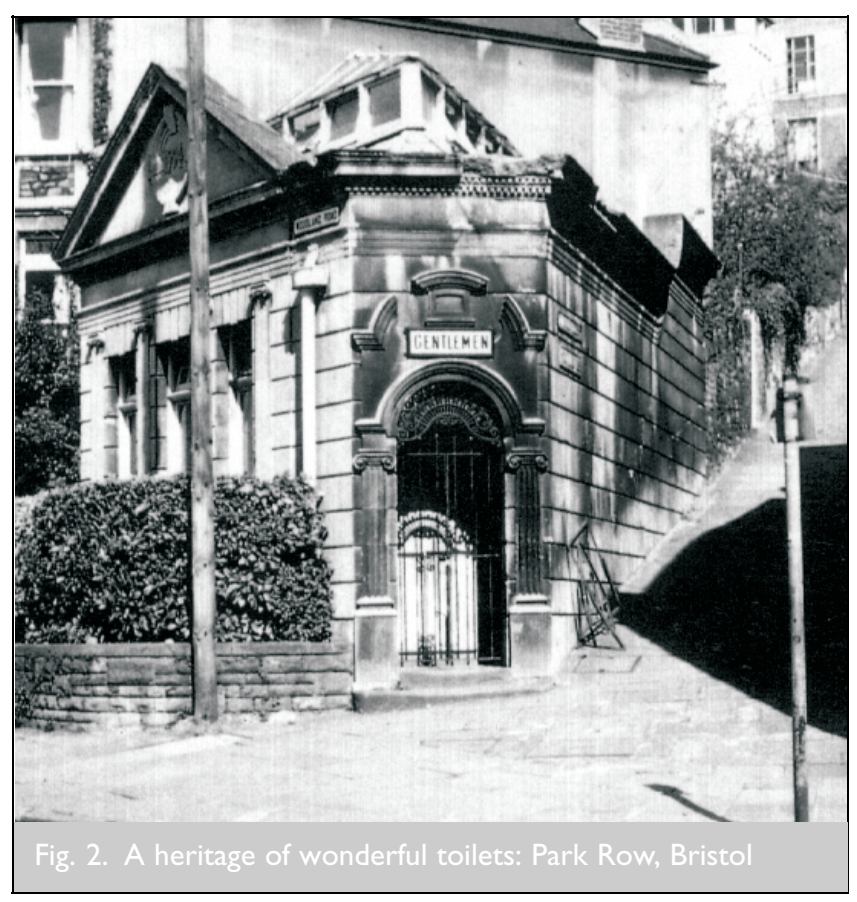


In contrast to 'abled toilet' codes covering 'disabled toilets' (toilets for those with disabilities) such as BS 8300, ${ }^{11}$ the DDA, and current revision of Part M of the Building Regulations, ${ }^{12}$ incorporate the highest standards and state-of-the-art thinking. However, no special guidance exists as to the distribution and location of disabled toilets. But it has been accepted practice to provide a 'disabled toilet' in locations where there are already 'abled' toilet facilities, interpreting guidance from the original Part $\mathrm{M}$ which said that 'toilet provision for the disabled should be equal to that for the abled. ${ }^{, 1,10}$

While enlightened local authorities are using DDA requirements as an opportunity to upgrade their 'abled' toilets, and to install baby-changing facilities as well, DDA requirements, as previously noted, are causing some local authorities to close their public toilets altogether. Legislation requiring mandatory provision, along with guidance on location and distribution, would result in a more consistent pattern nationally, rather than the variations in levels of provision which are to be found at present between different areas.

Lack of compulsory standards and clear toilet policies do not matter as long as those controlling toilet provision appreciate the importance of public toilets to the wider economy and society. After all, local authorities plentifully provided them in the past as a matter of course without the trouble it takes today. All sorts of other civic benefits and street furniture such as seats, flower beds, bus shelters, fountains are not compulsory either but they still get provided by enlightened councils. But when attitudes change, money is limited, and maintenance and management problems grow, local authorities readily 'forget' why the toilets were there in the first place; that is, to serve the general public and to discourage street urination.

\subsection{Unequal provision}

Guidance within BS 6465 Part I requires men to be provided with approximately a third more provision per unit of toilet space than women. Indeed simply giving the Ladies and the Gents equal floor space results in inevitable inequality because urinals take up less space than cubicles. Men have more facilities overall, as in some localities only a Gents is provided, and more facilities are provided for male customers than women in public houses, theatres and cinemas. Sports stadia provision for men in particular vastly outnumbers that available for women, $90: 10$ ( $\mathrm{m}$ : f ratio) being commonplace in traditional football grounds. ${ }^{13}$

Women make up the majority of public transport users, and are out and about shopping and using city centres more than men in the daytime, and they are often accompanied by babies, children and elderly relatives, and biologically they have more reasons to use the toilet than men. (About a quarter of all women of childbearing age are menstruating at any one time.) Therefore they are the majority of the users of public toilets, particularly in central areas. In a survey entitled WC Provision in Shopping Centres $^{14}$ undertaken to support revision of the BS 6465 Part I standards, shopping centre managers (including members of the BCSC (British Council of Shopping Centres)) reported that women regularly outnumber men by a ratio of $70: 30$ in shopping centres, with figures reaching $90: 10$ in some locations. The level of provision of toilets for women in town centres at 'best' (in rare instances) is likely to be on equal $50: 50$ levels, and more typically, on a $70: 30$ ratio in favour of men.

Yet there is less public provision for women than men in many cities. Men are also more able to use a range of bar, club and pub toilet facilities, especially in the evenings. Women with small children may be effectively barred from using such facilities because of the licensing laws, whereas many a woman on her own would be wary of entering a 'strange pub' because of personal safety concerns. Some men and women are unwilling to go into fast-food restaurants, licensed premises, or entertainment venues to use the toilets, for a variety of religious, dietary and cultural reasons.

Not only do women have fewer facilities but they are also more likely to have to pay for them. The 1936 Public Health Act, s. 87, subs. 3 gave local authorities the right to build and run on-street 'public conveniences' and to charge such fees as they think fit 'other than for urinals.' Methods of collection have included penny-in-the-slot mechanisms and a variety of turnstile barriers, which were particularly unpopular in hindering access for those with pushchairs, suitcases and small children. After a heated campaign, turnstiles were eventually outlawed under the 1963 Public Lavatories (Turnstiles) Act. The rules banning turnstiles never did apply to private conveniences, only public ones, and they never applied to railway stations: hence the installation of turnstiles at most central London railway termini stations nowadays, much to the inconvenience of travellers. The introduction of payment barriers in some shopping malls, and the requirement of payment (by both men and women) for the use of APCs, are both matters of questionable legality.

\subsection{Management and policy structures}

Powers to provide 'away from home' toilets are fragmented, being held by a variety of public and private bodies, including retail facility managers, bus and railway station managers, car parking companies and local authorities. Many local authorities have inherited a hotchpotch of toilets which were built ad hoc at different times for a variety of reasons, which they have kept open as best they can against difficult odds.

Public toilet provision is not generally dealt with within local authorities by the higher-status policy departments concerned with city planning, transportation and strategic policy making. Rather, toilets are administered by a technical department such as street cleansing, parks and allotments or refuse collection. Although the work of such departments is essential to the smooth running of an authority, they often lack a strategic policy dimension.

It has been found from the research that many toilet authorities do not produce any written policies, location maps, or surveys of user demand. A technically orientated short-term approach prevails where officers respond quickly to problems of vandalism and disrepair, often by simply closing down the toilets and thus removing the problem, apparently with little thought as to where people are mean to go instead. Few toilet departments operate on the basis of longer-term social policy objectives which take into account user needs. 
There is no requirement that public toilet policy statements and location information must be included in any development plans or urban policy documents. However, planning gain is often used by planners as a means of ensuring that public toilets are provided in a new development (see s. 106 Agreements on pp. $152-153$ of Reference 1), whereby the developer gets a more generous planning permission in return for providing social amenities). In this process the local authority becomes the enabler rather than the provider, and therefore does not have direct control on the continuance of provision.

However, some authorities do have a spatial toilet strategy of sorts, but this was often used to 'rationalise' and reduce the number of toilets available rather than to plan for a wider coverage and increase in facilities to meet the demands of modern travel patterns. For example, in the Nuffield research study $^{3}$ it was found that one local county had a location policy based upon putting toilets into three locational categories, namely those in strategic toilet locations (on main roads and in central areas), tourist areas, and local districts. In the course of the cost-cutting rationalisation process the local ones were most likely to be closed, as they were seen as the least important. Centralisation and concentration of toilet provision to achieve economies of scale can result in provision being out of reach of local residents, particularly if they are travelling by foot, bicycle or bus.

In contrast, city planning departments may be more aware of social issues and hold a wider policy perspective. Yet, in spite of their protestations of operating 'joined-up thinking' they may never consider toilets; indeed, the topic may be seen as a joke. But it is argued that public toilets have a crucial role in shaping the levels of access, mobility and usability of modern cities. Clearly there is a need for more liaison between departments.

\subsection{Cultural differences}

The level and nature of toilet provision is not only affected by matters of money and regulation; from the research it would seem that the subcultural values or 'world view' of the providers also strongly influences the outcome. Much of the literature and guidance found within the sanitary engineering world and within the municipal public works culture appears to be obsessed and fascinated by the details of plumbing, such as the size of piping, the amounts of water used in flushing, the minutiae of specifications of materials, dimensions, tolerances and so forth. Undoubtedly these factors are vital, but greater attention to human issues that affect users, such as the size of cubicles, height of pans, privacy matters, and access issues would result in better toilet design. When users are considered they are usually seen to be men, because most of those who are responsible for toilet design, provision and management are male too (as are most of their respective professional and technical bodies). ${ }^{15}$

Provision of Ladies' toilets is often seen as an awkward, embarrassing topic, that creates extra facilities and costs. This appears to be reflected in the final design output. For example, generally the cubicles in the Ladies are too small. One of the most annoying problems for women in public toilets is the lack of space between the edge of the door and the front rim of the toilet pan (Fig. 3). In Ladies' toilets a major problem is the location of sanitary waste bins which are required under environmental

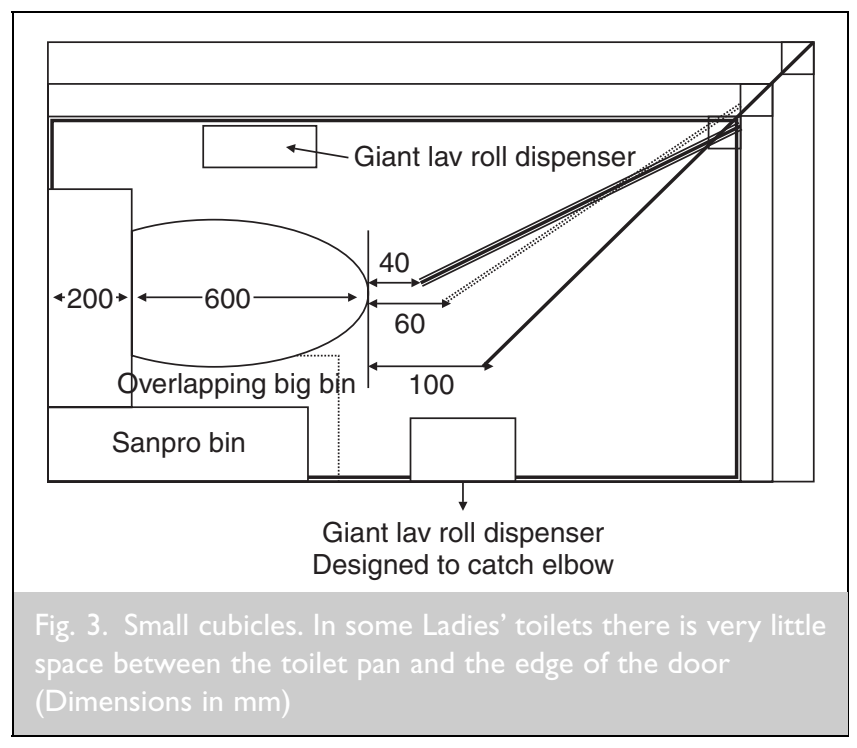

controls. The bin is often squashed in between the wall and the side of the toilet seat-touching the seat. Some bins are taller than the top of the toilet seat as well as sloping outwards as they rise. Thus they block access one side of the seat by the user, making it impossible for a woman to sit on the seat (Fig. 4). This is but one example of the fragmentation of decision making found in toilet design, with apparently little input from a female-user perspective.

People with disabilities have much criticised toilet designers for lack of understanding of the range and nature of disabled users' needs. For example, disabled women can have very different toilet design requirements from their male counterparts, not least because of the need to sit on the seat to urinate. Likewise the needs of ethnic minority users are not identical; indeed, they vary according to religion, age, class, gender and culture. Some local authorities, such as in Sheffield, are already committed to providing at least one cubicle containing a squat toilet (sometimes called a Turkish toilet) in public conveniences located in ethnic minority areas. In toilet blocks where such facilities are provided it is important to make sure there is not a gap at the bottom of the toilet door for modesty reasons. Indeed privacy is a very important issue to Muslim women in particular. More broadly, women from the full range of religious and secular

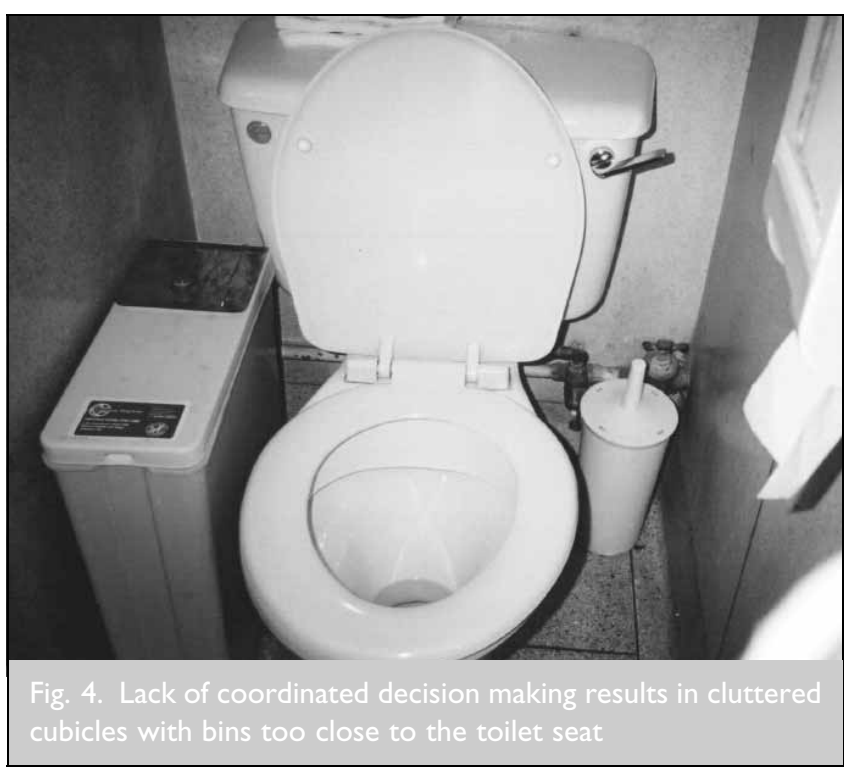


groups are also wary of unisex toilets, where they are expected to share toilet facilities with male strangers. Ideally separate male/ female facilities should always be provided with maximum privacy for all users.

\section{TOILET PROVISION POLICY: WHAT SHOULD BE DONE?}

\section{I. Levels of provision}

People often ask, 'but how many toilets should we provide?' British Toilet Association (BTA) members have previously recommended that ${ }^{16}$

\begin{abstract}
... a local authority should provide no fewer than 1 cubicle per 500 women and female children and one cubicle and one urinal per 1100 men, and no fewer than one unisex cubicle for use for people with disabilities per 10000 population and no fewer than one unisex nappy changing facility per 10000 people dwelling in the area.
\end{abstract}

The relevant population in question should include commuters, tourists and visitors as well as residents. This standard can be used in calculating facilities relative to town centres, shopping streets, railway passenger needs, bus stations, car parks and so forth.

However, the solution may not be as simple as suggested above. The question of 'how many?' has also taxed the members of the BS 6465 Part I revision committee, in developing standards for public toilets, because unlike toilets in buildings, where floor space might be used, there is no fixed catchment cut-off point for public toilets. Although area is an important consideration, factors such as footfall, demand, user composition, density of development and surrounding land uses must be taken into account.

Further, concentration and frequency of use are also key factors. Some quite remote, sparsely populated locations may suddenly get an influx of large numbers of tourists on coach trips who all want to go to the toilet within a short space of time. Levels of demand at particular times in the day must also be taken into account, particularly in places of public entertainment, sport and leisure where there might be heavily concentrated use during intervals. The question of intensity of use is particularly important in locations where women predominate, because according to research past and present, ${ }^{17,18}$ women take twice as long to urinate ( $80 \mathrm{~s}$ ) as men (40 s). So queues can rapidly build up, even if women have the same number of facilities as men. Therefore in the Far East where a restroom revolution is taking place, for example in parts of Japan and Korea, a 2:1 ratio in favour of women has been introduced in popular tourist areas. ${ }^{6}$

\subsection{Toilet distribution}

Rather than perpetuating the current fragmented and inadequate nature of public toilet provision, in meeting the public toilet needs of the nation, it is vital to develop a strategic hierarchy of toilet provision, ranging from high levels of provision in city centres (Fig. 5), to at least a minimum of provision in smaller settlements and rural areas. To do so it is essential to develop an overall toilet strategy which includes all sources of provision, be they public or private, on-street or off-street. This strategy should be an integral component of urban policy, administered by the city planning department, with toilet policies mainstreamed into

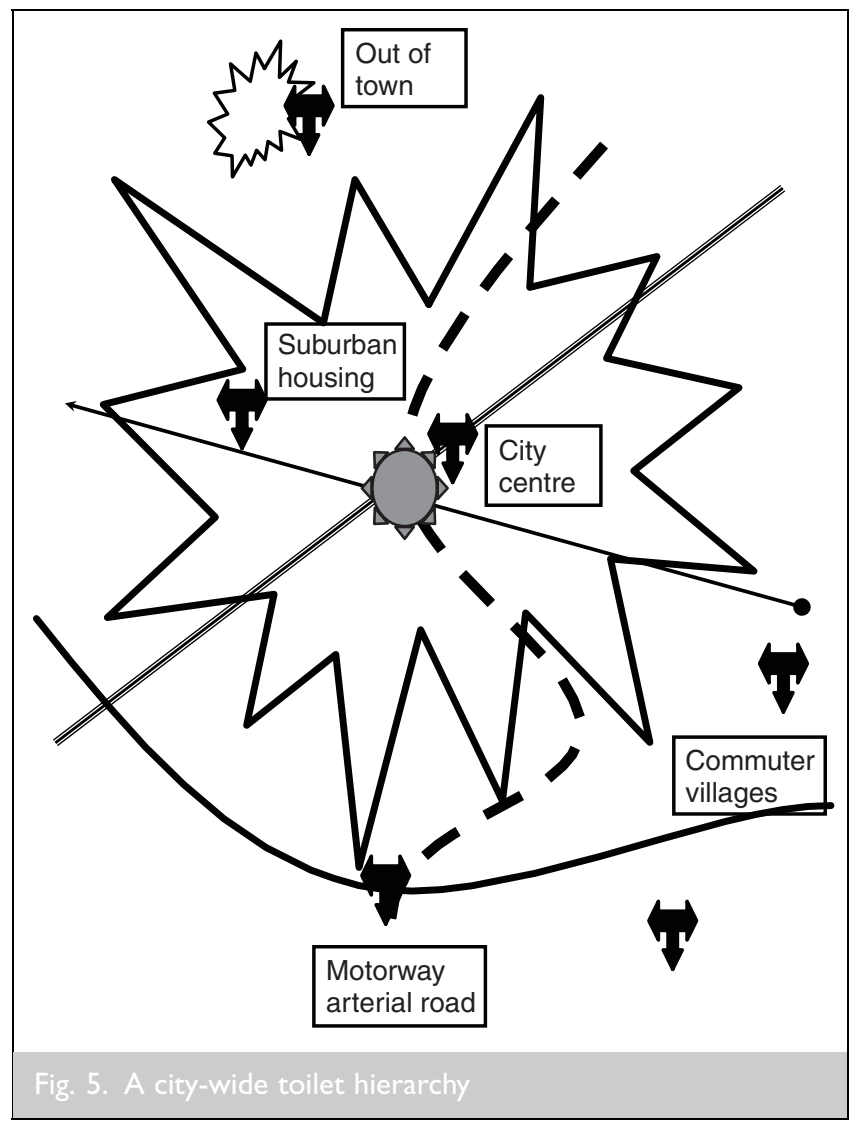

the planning policy documents and shown on all development plans and local area plans. Public toilets need to be seen as a core component of transport planning and a key factor in the creation of sustainable cities. Table 1 summarises the principles of a strategic toilet hierarchy.

\subsection{Toilet location and siting}

While this paper argues for compulsory standards, a degree of professional expertise is needed in determining where toilet blocks should be located. A thorough survey should be undertaken to identify suitable toilet locations, likely user composition, age and needs, possible problems, and future demand trends. ${ }^{19}$ In deciding where to site a new toilet block the

Public toilets should be provide in:

- All main public transport termini and stations and major car parks

- Central areas, and in all district centres, and local shopping centres

- All parks, allotments, urban farms and leisure areas

- At main junctions and by post offices in all suburban areas

- Out-of-town developments in office, industrial and retail parks

- In all villages with over 5000 population and every 3 miles along main roads

- User consultation and public participation should shape toilet policy making

- In summary, toilet 'hotspots' should be identified and concentrated upon

- A toilet strategy, an overall plan setting out the hierarchy, location and distribution of public toilets, should be provided for every local authority as part of mainstream urban policy 


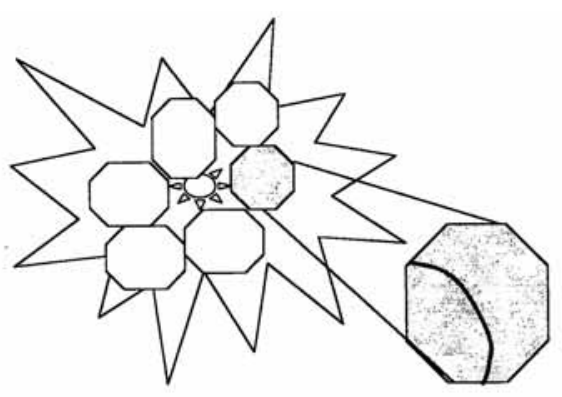

Explanation: This is a condensed diagrammatic sketch of a district centre, which comprises one cell in the structure of the city.

Principle: Adequate toilets should be provided for each different user group, for example not everyone can or wants to go into a pub, and there should be adequate toilets for both public transport users and car users.

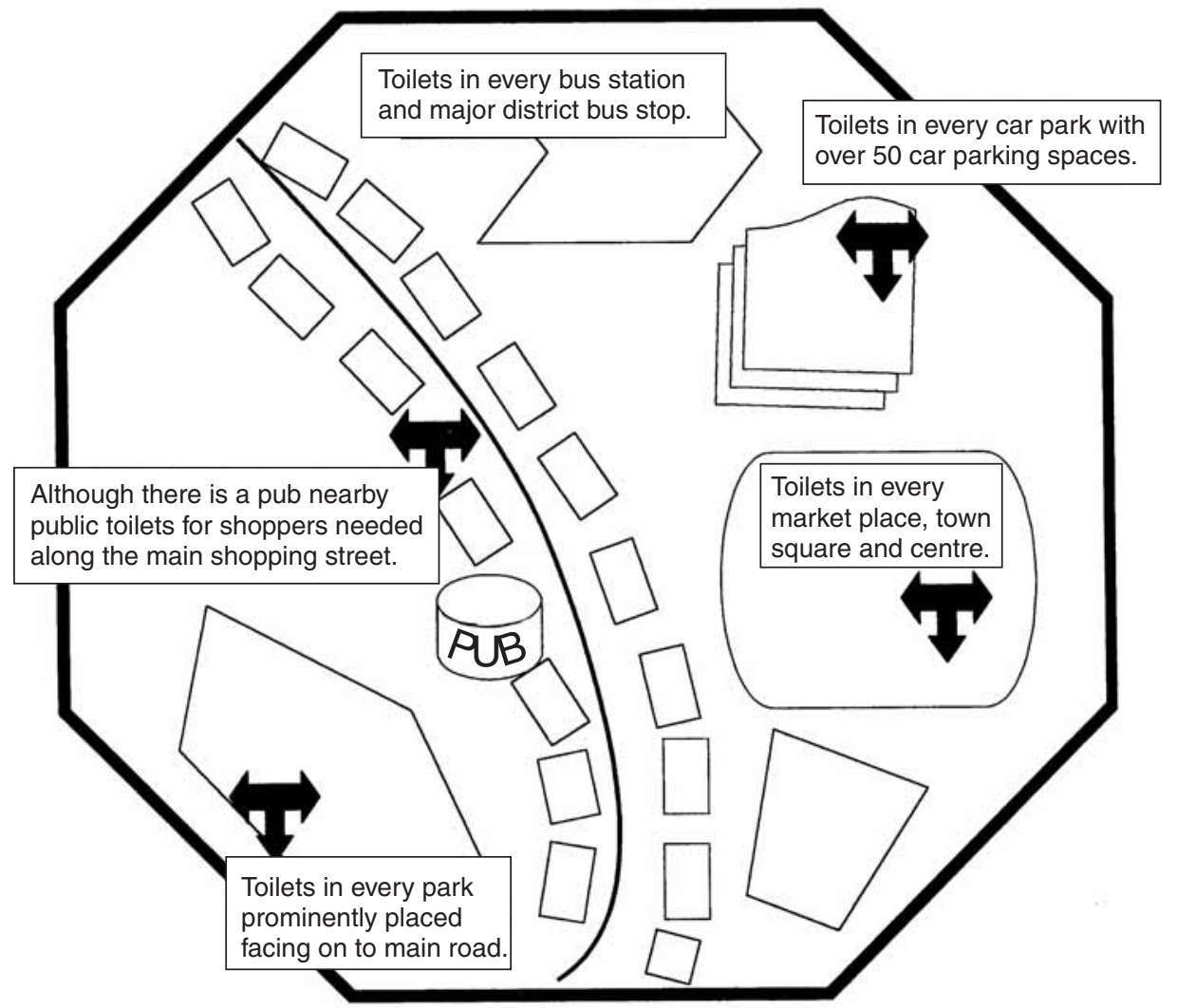

principles of good urban design should be maintained. ${ }^{20}$

Thorough site appraisal should be carried out as would be the case for any 'normal' development using all the normal skills of urban design. ${ }^{21}$ Toilets should be located prominently in public thoroughfares and squares, in open, well-lit areas (Fig. 6). ${ }^{20}$ Increased foot flow past the toilets is likely to reduce loitering and increase overall surveillance and integration with other land uses. Toilet attendants are essential and have been shown to be cost-effective in reducing the levels of vandalism and thus the need for repair. ${ }^{3}$

Access considerations should be taken into account throughout. Ideally all toilets should be positioned at street level, not down steps and not at long distances from the main focal points of human activity (Fig. 7). Ramps should be provided where there is no alternative to a gradient change. The area around the toilet should be free from clutter and well lit. Such an approach requires managerial liaison between the departments responsible for different aspects of the street environment. Internal design is not discussed further as the purpose of this paper is to highlight the deficiencies in provision and to propose legislative and organisational change. ${ }^{1}$

\section{HOW MIGHT THIS ALL BE DONE?}

\section{I. A mandatory legislation and regulation}

To achieve change the most pressing need is for a new Act of Parliament to be passed that would make public toilet provision compulsory. As actual standards are not normally found within Acts of Parliament, the legislation would need to be linked to new British Standards requirements and Building Regulations, with the Act stating that the revised standards would now be mandatory, not just advisory. Within reason they should also be made retrospective, following the lead of DDA requirements.

\subsection{Strategic planning}

While previous toilet regulations have given greater attention to internal and technical standards, a key component of future standards, reinforced by Act of Parliament, would be mandatory 


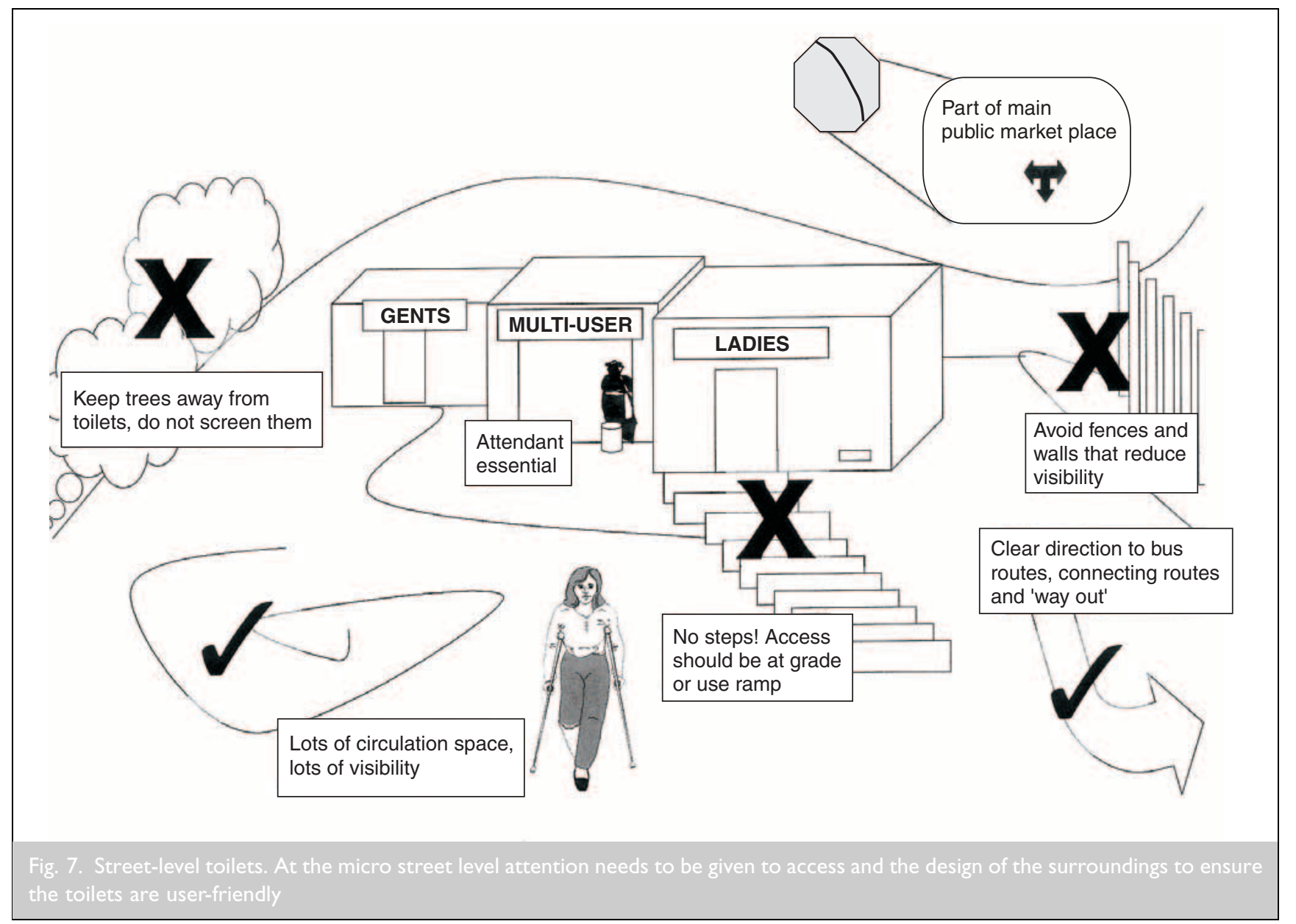

public toilet provision in respect of location and spatial distribution standards. Such standards have been developed and are in use in the Far East, both at central and local government level, especially in Japan where the toilet standards are an integral component of city planning policy. ${ }^{22,23}$

Local authorities would be required to undertake a survey of existing facilities, demand and user needs. On this basis a Toilet Strategy for the area would be produced, showing the hierarchy of provision and including all categories of 'away from home toilets' so as to reduce the current fragmentation and division of powers. A survey of user numbers and composition is now a compulsory component of complying with Scottish toilet building standard. ${ }^{24}$ The town and country planning acts would be amended accordingly to make this requirement an integral and compulsory component of all planning policy documents, development plans and local plans. The Toilet Strategy would be integrated into all sustainability and transportation policies in the city, as well as linking to leisure, sport, disability and equality policies within other departments of the local authority in question.

Institutional change would need to take place, with city planning departments taking overall responsibility for toilet policy and strategy, and liaising with technical departments responsible for provision. Partnering with private-sector providers of public toilets would be encouraged. Both design regulation and financial incentive would be introduced to ensure that all toilet providers were playing their part in achieving the Toilet Strategy in a locality. Both user and provider groups would be involved in consultation and policy-making processes in deciding the most effective locations for new public toilets.

\subsection{Equalities}

In accordance with Equal Opportunities Regulations, and European Union Directives on integrating equality issues into all legislation, the new Act should specify that equality of provision and resource allocation should be provided by all local authorities in respect of the needs of women and men. ${ }^{25} \mathrm{In}$ practice this may mean varying ratios of provision according to the location and composition of user groups. To comply with equal treatment requirements, women should not have to queue longer than men to use the facilities. Amendments would need to be made to a range of current statutes to incorporate toilet provision equality, including disability, gender, ethnicity, employment, education and health legislation.

Amendments would also be needed to a range of design codes, building regulations, British Standards, and Planning Policy Guidance Notes, to create a more inclusive approach to toilet provision for everyone, including those who cannot access standard toilets because of being accompanied by pushchairs, small children, elderly relatives or suitcases, or those who are suffering temporary illnesses but are currently not eligible to use the disabled toilets. Therefore an inclusive approach to toilet provision is recommended, allowing for the full range of needs and levels of ability, while still prioritising dedicated provision for the disabled. ${ }^{26}$ 


\subsection{Finance}

Archaic sections in previous toilet legislation should be repealed, not least the requirement that only women are required to pay to urinate. It is another enormous debate as to whether everyone should pay or not. Payment systems tend to reduce accessibility by creating barriers, and may actually cost more to run than the amount collected. Many would argue that payment at source through the rates and taxation, rather than at point of delivery at the toilet door, is more equitable (in the same way one does not pay to walk on the pavement or sit on a park seat). ${ }^{27}$

There would, however, need to be adequate finance for the increased levels of toilet provision brought about by the proposed legislative changes. At local authority level, funding would need to be protected and ring-fenced specifically for toilet provision. Since many local authorities do not have adequate resources, it is recommended that central government would provide subsidies specifically for toilet building and repair. Both local-authorityrun toilets, and private-sector 'public toilets' would be eligible for central government funding. Otherwise, as with so much disability legislation, those responsible for facilities will do their best to avoid implementing change because of lack of finance.

\subsection{Cultural change}

In order for all these proposals to be adopted there needs to be a major cultural change in the way that public toilets are perceived by policy makers and within British culture as a whole. Rather than seeing toilets as waste of money, they need to be seen as a positive, value-added component of urban infrastructure. Studies have shown that towns that provide good toilets increase their visitor rates and retail turnover. ${ }^{28}$ In spite of the business case for increased provision, there still needs to be a change in political will to bring about legislative change.

If our public transport system, infrastructure, toilets, and other public services are in a state of chaos this sends out a strong message to the rest of the world that Britain is in decline. As Lewis Mumford, the famous town planner, is rumoured to have said, 'a civilisation may be judged by the way it disposes of its waste'. ${ }^{29}$ Likewise the Director of the British Toilet Association has commented, 'you can judge a nation by its toilets'. Therefore, in conclusion, providing better public toilets not only meets the needs of the local population but also enhances the reputation of the nation internationally, encourages more tourists, visitors and investors and thus brings financial as well as environmental and social benefits.

\section{REFERENCES}

1. Greed C. Inclusive Urban Design: Public Toilets. Architectural Press, Elsevier Publications, Oxford, 2003.

2. British Toilet Association. Better Public Toilets: $A$ Providers' Guide to the Provision and Management of 'Away from Home' Toilets (Fowler R. (ed.)). BTA, Winchester, 2001.

3. Greed C. and Daniels I. User and Provider Perspectives on Public Toilet Provision. Report of Nuffield Trust Research, Occasional Paper, Faculty of the Built Environment, University of the West of England, Bristol, 2002.

4. Hanson J. and Greed C. Inclusive design of public toilets in city centres. Workpackage 9, EPSRC Research Project,
Vivacity: Sustainable Urban Environments-Urban Sustainability for the Twenty-four Hour City. Engineering and Physical Science Research Council, London, 2003.

5. Central Cities Institute. Licensing Reform. University of Westminster, London, 2002.

6. Greed C. Downtown restrooms. Proceedings of New Beginnings for the 21st Century Toilet: World Toilet Summit 2002, Korean Clean Toilet Association, Seoul, 2002, 171 179.

7. HANSON J. and GREED C. Accessible public toilets in city centres. Access by Design, 2003, Issue 95, 24-27. Centre for Accessible Environments, London.

8. GREed C. Planning for accessibility. In Disability: Making Buildings Accessible-Special Report (BRIGHT K. (ed.)). Workplace Law Group, London, 2004, 37-46. Available on the internet at: www.workplacelaw.net

9. Department of the Environment. Approved Document G: Hygiene in The Building Regulations. HMSO, London, 1995. (Amended version.)

10. Department of the EnVironment. Access and Facilities for Disabled People: Approved Document M. HMSO, London, 1992. (See Office of the Deputy Prime Minister, 2003 entry for updated version.)

11. British Standards Institution. Design of Buildings and their Approaches to Meet the Needs of Disabled People: Code of Practice. BSI, London, 2001, BS 8300: 2001.

12. Office of the Deputy Prime Minister. Access and Facilities for Disabled People: Approved Document M. HMSO, London, 2003 (revised document).

13. Inglis S. Toilet Facilities at Stadia: Planning, Design and Types of Installation. Sports Council in association with the Football Trust, London, 1993.

14. British Standard Revision Committee. WC Provision in Shopping Centres. (Survey to support revision of BS 6465.) BSRC, London, forthcoming 2004.

15. Institute of Plumbing. Looking at women's needs. Plumbing, 2003, Nov./Dec., pp. 9-10. IOP, London, reporting on the work of Griggs J., Barclay M. and Greed C. on the BS 6465 Part I Revision Committee.

16. Cunningham S. and Norton C. Public Inconveniences: Suggestions for Improvements. All Mod Cons and the Continence Foundation, London, 1993.

17. KIRA A. The Bathroom. Penguin and Cornell University Press, Harmondsworth, 1976.

18. Asano Y. Numbers of Toilet Fixtures: Mathematical Models and Queuing Theory. Faculty of Architecture and Building Engineering, Shinshu University, Nagano, Japan, 2002.

19. Robinson S. Public Conveniences: Policy, Planning and Provision. Institute of Wastes Management, London, 2001.

20. GReed C. and Roberts M. Introducing Urban Design. Longmans, Harlow, 1998.

21. Roberts M. and Greed C. Approaching Urban Design. Pearson, Harlow, 2001.

22. Miyanishi Y. Comfortable Public Toilets: Design and Maintenance Manual. City Planning Department, Toyama, Japan, 1996.

23. Sнiонiко T. Toilets in sightseeing areas. Proceedings of the Taiwan Toilet Association Conference: Mountain Toilet and Tourist Toilet, Taipei, 2003, 51-60.

24. Building Regulations Office. Part $M$ of the Technical Services Standards for Compliance with the Building 
Standards (Scotland) Regulations 1990 as Amended. Building Regulations Office, Edinburgh, 2003.

25. ReEves D. and Greed C. (eds). Gender Mainstreaming in Planning: Toolkit and Research Report. Royal Town Planning Institute, London, 2003. Available on the internet at: www.rtpi.org.uk

26. Goldsmith S. Universal Design. Architectural Press, London, 2001.
27. EDWARDS J. Policy making as organised irresponsibility: the case of public conveniences. Policy and Politics, 1998, 26, No. 3, 307-320.

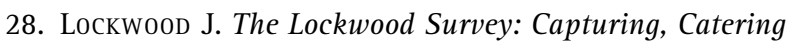
Caring for Consumers. Urban Management Initiatives, Town Centre Management, Huddersfield, 2003.

29. Mumford L. The City in History. Penguin, Harmondsworth, 1965.

Please email, fax or post your discussion contributions to the secretary by I December 2004: email: kathleen.hollow@ice.org.uk; fax: + 44 (0)20 7799 1325; or post to Kathleen Hollow, Journals Department, Institution of Civil Engineers, I-7 Great George Street, London SWIP 3AA. 